\title{
Outcome in Patients of Diabetic Foot Infection with Multidrug Resistant Organisms
}

\author{
${ }^{1}$ Sanjay Gupta, ${ }^{2}$ Ashok Attri, ${ }^{3}$ Sudhansoo Khanna, ${ }^{4}$ Jagdish Chander, ${ }^{5}$ Mayankjayant
}

\begin{abstract}
Aim and objectives: To study the spectrum of microorganisms in patients of diabetic foot infection (DFI) and to evaluate the outcome in patients of DFI with multidrug resistant organisms (MDRO).

Materials and methods: A total of 116 patients, visiting diabetic foot clinic of our institute with DFI were observed in a prospective manner. Diagnosis of infection was based on clinical findings using International Working Group on Diabetic Foot and Infection Diseases Society of America (IWGDF-IDSA). The microbiological profile of wound assessed at the time of admission and patients were followed up for wound healing rate, need for amputation and surgical interventions, hospital stay, and mortality for 6 months.
\end{abstract}

Observation and results: The microbiological profile of our patients showed that Gram-negative microorganisms were commonly isolated $(78.4 \%)$ from our patients. The culture trends revealed that most common isolates were E. coli (33.6\%), Pseudomonas (19.8\%), Proteus (18\%), Klebsiella (16\%), Acinetobacter and Citrobacter among the Gram-negative organisms. Among Gram-positive organisms, Staphylococcus aureus was the most common isolate which was present in 29 (25\%) of the patients. MDRO were isolated from $13.8 \%$ of patients. Most common MDRO isolated were methicillin-resistant $S$. aureus (MRSA) and vancomycin-resistant Enterococci (VRE). The outcome was assessed in terms of mortality rate, the rate of major amputation, rate of minor amputation, the rate of multiple surgical interventions, duration of hospitalisation and requirement of intensive care unit (ICU) admission, re-admission rate, antibiotic requirement which were not significantly different in patients with MDRO than that with non-MDRO ( $p$-value > $0.05)$. The mean healing rate in patients with MDRO was not significantly different than that from patients with non-MDRO (p-value > 0.05).

Conclusion: Although the number of patients with MDRO is small as compared to non-MDRO, the study found that MDRO has no significance on the outcome of the patients with DFI.

Keywords: Diabetic foot infection, Methicillin-resistant S. aureus, Multidrug-resistant organisms.

\footnotetext{
1,5 Associate Professor, ${ }^{2,4}$ Professor and Head, ${ }^{3}$ Senior Resident 1,2,3,5 Department of Surgery, Government Medical College and Hospital, Chandigarh, India

${ }^{4}$ Department of Microbiology, Government Medical College and Hospital, Chandigarh, India
}

Corresponding Author: Sanjay Gupta, Associate Professor, Department of Surgery, Government Medical College and Hospital, Chandigarh, India, e-mail: sandiv99@me.com
How to cite this article: Gupta S, Attri A, Khanna S, Chander $\mathrm{J}$, Mayankjayant. Outcome in Patients of Diabetic Foot Infection with Multidrug Resistant Organisms. J Foot Ankle Surg (Asia Pacific) 2018;5(2):51-55.

\section{Source of support: Nil}

Conflict of interest: None

\section{INTRODUCTION}

Approximately one-in-four people with diabetes develop a foot ulcer during their lifetime and as many as half of these ulcerations subsequently get infected ${ }^{1,2}$ Recently, MDRO are seen to b e increasingly associated with diabetic foot infection (DFI), which further complicates the management of diabetic foot syndrome. According to the Centre for Disease Control and Prevention (CDC), MDROs are defined as microorganisms, predominantly bacteria, that are resistant to one or more classes of antimicrobial agents. Most commonly encountered MDRO is methicillin-resistant Staphylococcus aureus (MRSA), vancomycin resistant Enterococci (VRE) and Gram-negative bacteria producing extended-spectrum beta-lactamases (ESBL), Metallo beta-lactamases (MBL). Although the names of certain MDROs describe resistance to only one agent (e.g., MRSA, VRE), these pathogens are frequently resistant to most available antimicrobial agents. ${ }^{3}$

Various studies have been conducted throughout the world to know the pattern and risk factors for the development of MDRO. MRSA is found to be the most common MDRO isolated from diabetic foot infections. The overall the prevalence of MRSAranges from 15-30\% depending on the geography. ${ }^{4}$ Large and deep ulcer, previous hospitalization and poor glycaemic control are identified as some of the risk factors responsible for developing an infection with these drug-resistant microorganisms. The emergence and spread of MDROs are of global concern. These infections require targeted antibiotic therapy for prolonged duration leading to a longer hospital stay, the overall cost of treatmentandadd to morbidity.However, there are conflicting results about the effect of MDRO on the ultimate outcome of DFI. Some studies have demonstrated that presence of MDRO has no significant impa ct on healing time of ulcers, ${ }^{5}$ others have demonstrated that mortality from infections with MDRO is twice as high as mortality from infections with microorganisms 
sensitive to antibiotics. ${ }^{6}$ The purpose of this study was to further determine the overall significance of MDROs in predicting outcome in patients with DFI.

\section{MATERIALS AND METHODS}

All patients of DFI attending the specialized clinic in our hospital from Ja nuary 2013 to December 2014 were included in the present study. Diagnosis of infection was based on clinical findings using IWGDF-IDSA. The patients were enrolledafter obtaining written and informed consent. A detailed performa was filled noting down the patient's relevant history, medical examination, and diabetic status. A complete hemogram, renal function tests, blood sugars, $\mathrm{HbA1c}$ levels, and X-ray foot were performed in all patients.

Neurological examination was done using Biothesiometer for vibration and temperature sensations and 10 gm monofilament for pressure. The vascular assessment was done using the Ankle-Brachial Index (ABI)/Doppler examination. The peripheral vascular disease was diagnosed, if $\mathrm{ABI}<0.8$. The ophthalmoscopic examination was done to diagnose retinopathy. Pus/necrotic material was obtained from a deep portion of the wound after drainage or debridement of the wound. Bone chips, if obtained were also sent for the cultures.

The enrolled patients were followed up regularly according to their clinical status and were assessed based on a percentage of wound healing, reinfection, readmission, reintervention, and antibiotic therapy requirement, at a monthly interval for 6 months.

\section{Microbiological Study and Methods}

The wound swabs were taken after superficial debridement to avoid ulcer colonization. Specimens were taken using sterile swabs introduced deep into the wound. Only the bacteriological results from these initial swabs were considered to characterize MDRO status on admission. Standard microbiological procedures were performed for all swabs to isolate the pathogenic bacteria, anaerobic bacteria, and fungi.

\section{Bacterial Isolation}

Gram's staining and aerobic culture were put for all the swabs. Blood agar and MacConkey media were used for primary isolation. The growth of bacteria was further confirmed by characteristic growth on blood agar, MacConkey agar, Gram's staining, and various biochemical tests.

Antibiotics susceptibility to routinely used antimicrobial was done by Kirby-Bauer susceptibility method. Testing for MDRO was carried according to Clinical and Laboratory Standards Institute (CLSI) criteria and standard protocols. MRSA, VRE, Gram-negative bacteria producing ESBL and Pseudomonas species and Acinetobacter species producing MBL were considered as MDRO.

\section{Statistical Analysis}

The study was carried out in a prospective observational manner and statistical analysis of the data was done at the end of the study using appropriate statistical tests depending on the variables. Quantitative data were presented as mean \pm SD and range or median and interquartile range, as appropriate. Normality of quantitative data was checked by measures of Kolmogorov-Smirnov tests of normality. For normally distributed data, means were compared using independent t-test. For skewed data or scores, Mann-Whitney U-test was applied. For discrete categorical data, number and percentages were calculated. Chi-square test or Fisher's exact test were applied for categorical data. All statistical tests were two-sided. A p-value of $<0.05$ was considered to indicate statistical significance. The analysis was conducted using Statistical Package for Social Sciences (SPSS) for Windows (version 17.0; SPSS Inc., Chicago, IL, USA).

\section{OBSERVATIONS AND RESULTS}

A total of 116 patients were enrolled in this study. The demographics and clinical characteristics of the patients based on bacteriological results of initial swabs is given in Table 1. The patients with negative culture report were excluded from this study (6 patients). Patients were classified as per IWGDF-IDSA classification into mild, moderate and severe DFI. Mild infection was present in $2(1.7 \%)$ patients, moderate infection was present in 70 $(60.3 \%)$ patients and severe infection was present in 44 $(37.9 \%)$ patients.

\section{Microbiology}

The microbiological findings on admission are given in Table 2. The microbiological profile of our patients showed that mono-microbial growth was present in 75 $(64.6 \%)$ patients and poly-microbial growth was present in $41(35.34 \%)$ patients. The culture trends revealed that most common isolates were E. coli $(33.6 \%)$, Pseudomonas (19.8\%), Proteus (18\%), Klebsiella (16\%), Acinetobacter and Citrobacter among the Gram-negative organisms. Among Gram-positive organisms, Staphylococcus aureus was the most common isolate which was present in 29 (25\%) of the patients. $48.27 \%$ of Staphylococcus aureus were MRSA. MDRO were present in 16 (13.8\%) patients, out of which 14 patients had MRSA and 3 patients had VRE. One patient had both MRSA and VRE. Anaerobic cultures were sent 
Outcome in Patients of Diabetic Foot Infection with Multidrug Resistant Organisms

\begin{tabular}{|c|c|c|c|}
\hline & $\begin{array}{l}\text { MDRO } \\
N=16 \\
(13.8 \%)\end{array}$ & $\begin{array}{l}\text { Non- } \\
\text { MDRO } \\
N=100 \\
(86.2 \%)\end{array}$ & $\begin{array}{l}p \text { - } \\
\text { value }\end{array}$ \\
\hline Age (years) (mean +/-SD) & $54.88+/-9.7$ & $\begin{array}{l}56.06+/- \\
11.38\end{array}$ & 0.695 \\
\hline Male & $10(62.5)$ & $76(76)$ & \multirow{2}{*}{0.252} \\
\hline Female & $6(37.5)$ & $24(24)$ & \\
\hline Pain & $9(56.3)$ & $43(43)$ & 0.322 \\
\hline Swelling & $13(81.3)$ & $86(86)$ & 0.703 \\
\hline Ulcer & $10(62.5)$ & $53(53)$ & 0.479 \\
\hline Gangrene & $7(43.8)$ & $56(56)$ & 0.361 \\
\hline Discharge & $12(75)$ & $73(73)$ & 1.00 \\
\hline Fever & $10(62.5)$ & $49(49)$ & 0.316 \\
\hline Neuropathic & $11(68.8)$ & $56(56)$ & 0.338 \\
\hline Neuroischemic & $5(31.3)$ & $40(40)$ & 0.505 \\
\hline History of DFI & $10(62.5)$ & $43(43)$ & 0.146 \\
\hline History of trauma & $4(25)$ & $36(36)$ & 0.572 \\
\hline $\begin{array}{l}\text { History of surgical } \\
\text { intervention }\end{array}$ & $9(56.3)$ & $35(35)$ & 0.104 \\
\hline Previous antibiotic use & $8(50)$ & $43(43)$ & 0.6 \\
\hline $\begin{array}{l}\text { Duration of DM (years) } \\
\text { [mean+/-SD] }\end{array}$ & $11.53+/-6.59$ & $\begin{array}{l}10.85+/- \\
7.01\end{array}$ & 0.719 \\
\hline BMI $\left(\mathrm{Kg} / \mathrm{m}^{2}\right)($ mean+l-SD) & $23.86+/-4.4$ & $24.4+/-3.8$ & 0.607 \\
\hline HbA1C (mean+/-SD) & $9.4+/-1.9$ & $\begin{array}{l}10.16+/- \\
2.39\end{array}$ & 0.278 \\
\hline Retinopathy & $14(87.5)$ & $68(68)$ & 0.144 \\
\hline Nephropathy & $3(18.8)$ & $14(14)$ & 0.703 \\
\hline Foot deformity & $3(18.8)$ & $23(23)$ & 1.00 \\
\hline Osteomyelitis & $1(6.3)$ & $16(16)$ & 0.461 \\
\hline
\end{tabular}

only for 65 patients due to technical reasons. None of the specimen reported positive for anaerobes.

\section{Outcome in DFI (MDRO versus non-MDRO)}

There was no statistically significant in the two groups with respect to demographic, clinical characteristics and risk factors (Table 1). The outcome of patients with DFI was assessed in terms of mortality, major amputation, minor amputation, requirement of multiple surgical interventions, duration of hospitalization and requirement of ICU admission, healing rate and follow-up and has been summarized in Table 3. None of the parameters was found to be statistically different between the two groups.

Mortality was seen in $6.25 \%$ patients with MDRO and $3 \%$ of patients with non-MDRO (p-value $=0.532$ ). Major amputation was required in $18.8 \%$ of patients with MDRO and 19\% of patients with non-MDRO, but this difference was statistically not significant ( $p$-value $=1$ ). Minor amputation was done in $25 \%$ of patients with MDRO and in $46 \%$ of patients with non$\mathrm{MDRO}$, but this difference was also not significant on statistical analysis ( $\mathrm{p}$-value $=0.174$ ). Multiple surgical interventions were required in $50 \%$ of patients with $\mathrm{MDRO}$ and $48 \%$ of patients with non-MDRO (p-value =

\begin{tabular}{|c|c|c|c|}
\hline Spectrum & $\begin{array}{l}\text { Number } \\
\text { of } \\
\text { patients }\end{array}$ & $\begin{array}{l}\text { Percentage } \\
(\%) \text { of } \\
\text { patients } \\
(N=116)\end{array}$ & $\begin{array}{l}\text { Relative } \\
\text { percentage } \\
(\%) \text { of } \\
\text { isolates } \\
(N=160)\end{array}$ \\
\hline Mono-microbial & 75 & 64.6 & \\
\hline Poly-microbial & 41 & 35.34 & \\
\hline Candida & 3 & 2.6 & \\
\hline \multicolumn{4}{|l|}{ Gram-negative } \\
\hline E. coli & 39 & 33.6 & 24.375 \\
\hline Klebsiella & 19 & 16.4 & 11.875 \\
\hline Proteus & 21 & 18.1 & 13.125 \\
\hline Pseudomonas & 23 & 19.8 & 14.375 \\
\hline Acinetobacter & 7 & 6 & 4.375 \\
\hline Citrobacter & 8 & 6.9 & 5 \\
\hline \multicolumn{4}{|l|}{ Gram-positive } \\
\hline $\begin{array}{l}\text { Staphylococcus } \\
\text { aureus }\end{array}$ & 29 & 25 & 18.125 \\
\hline Enterococci & 11 & 9.5 & 6.875 \\
\hline $\begin{array}{l}\text { Total number of } \\
\text { isolates }\end{array}$ & 160 & & \\
\hline $\begin{array}{l}\text { Number of isolates/ } \\
\text { patient }\end{array}$ & 1.37 & & \\
\hline \multicolumn{4}{|l|}{ MDRO } \\
\hline MDRO & 16 & 13.8 & \\
\hline MRSA & 14 & 12.1 & \\
\hline VRE & 3 & 2.58 & \\
\hline
\end{tabular}

0.887). The mean duration of hospital stay in patients with MDRO was $19.15+/-12.95$ days which is slightly more than that in patients with non-MDRO (17.65 +/- 8.05 days) $(p$-value $=0.968)$. The requirement of ICU admission was not seen in any patients with MDRO however $3 \%$ patients with non-MDRO required ICU admission ( $p$-value $=1$ ).

Mean healing rate at the 6th month of follow-up in patients with MDRO was $91.25 \%$ and in patients with non-MDRO was $88.29 \%$, however, this difference was statistically not significant ( $p$-value $=0.504)$ (Table 4 and Fig. 1). Similarly, during follow-up visits rate of reinter-

Table 3: Outcome in patients with MDRO versus non-MDRO

\begin{tabular}{|c|c|c|c|c|}
\hline Outcome & $\begin{array}{l}\text { Total } \\
N=116 \\
(100 \%)\end{array}$ & $\begin{array}{l}\text { MDRO } \\
N=16 \\
(13.8 \%)\end{array}$ & $\begin{array}{l}\text { Non- } \\
\text { MDRO } \\
N=100 \\
(86.2 \%)\end{array}$ & $\begin{array}{l}p \text { - } \\
\text { value }\end{array}$ \\
\hline Mortality & $4(3.4)$ & $1(6.25)$ & $3(3 \%)$ & 0.532 \\
\hline $\begin{array}{l}\text { Major } \\
\text { Amputation }\end{array}$ & $\begin{array}{l}22 \\
(18.96)\end{array}$ & $3(18.8)$ & $19(19)$ & 1.00 \\
\hline $\begin{array}{l}\text { Minor } \\
\text { Amputation }\end{array}$ & $50(43.1)$ & $4(25)$ & $46(46)$ & 0.174 \\
\hline $\begin{array}{l}\text { Multiple } \\
\text { Surgical } \\
\text { interventions }\end{array}$ & $\begin{array}{l}56 \\
(48.27)\end{array}$ & $8(50)$ & $48(48)$ & 0.887 \\
\hline $\begin{array}{l}\text { Duration } \\
\text { of hospital } \\
\text { stay (days) } \\
\text { (mean+/-SD) }\end{array}$ & $\begin{array}{l}17.87+/- \\
8.85\end{array}$ & $\begin{array}{l}19.15+/- \\
12.95\end{array}$ & $\begin{array}{l}17.65+/- \\
8.05\end{array}$ & 0.986 \\
\hline ICU stay & $3(2.58)$ & $0(0)$ & $3(3)$ & 1.00 \\
\hline
\end{tabular}


Table 4: Mean healing rates (MDRO versus non-MDRO)

\begin{tabular}{llll}
\hline \multirow{2}{*}{$\begin{array}{l}\text { Follow up visit } \\
\text { (months) }\end{array}$} & \multicolumn{2}{l}{ Mean healing rate (\%) } & \\
\cline { 2 - 3 } 1st & MDRO & Non-MDRO & p-value \\
2nd & 25.71 & 27.22 & 0.64 \\
3rd & 47.5 & 44.68 & 0.604 \\
4th & 66.25 & 58.47 & 0.247 \\
5th & 78.85 & 72.29 & 0.286 \\
6th & 89.62 & 79.71 & 0.07 \\
\hline
\end{tabular}

vention, readmission and antibiotic requirement were also compared at monthly intervals between the two groups. However, no significant difference was identified between the two groups.

\section{DISCUSSION}

The present study confirmed that the prevalence of MDRO infection is not uncommon among diabetic foot ulcer patients. MDROs were present in $13.8 \%$ of the patients. $48.27 \%$ of Staphylococcus aureus were MRSA, and $27.27 \%$ of Enterococci were VRE. The reported prevalence of MRSA in DFI range from 5 to $30 \%$, and there is an alarming trend for the increase in many countries. ${ }^{4}$ In India incidence of MRSA shows variation from 6 to $81 \%{ }^{7}$ The impact of this multidrug resistance on morbidity and mortality in DFI is debatable. As compared to infection with drug-susceptible bacteria, MDRO infections have been shown to increase hospital stay and $\operatorname{cost}^{8}$ and, in some cases, to be associated with increased morbidity or increased death rates. ${ }^{9}$ Contrary to this, other studies have reported similar attributable mortality rates to drug-resistant and drug-susceptible organisms. ${ }^{10,11}$ Sanchez et al. observed that there is no significant difference between mortality in patients with and without MRSA ( $0 \%$ and $1.6 \%$ respectively) with a p-value of $0.45 .^{12}$ We also observed $6.25 \%$ mortality with $\mathrm{MDRO}$ and $3 \%$ of patients with non-MDRO, the difference was statisticallynon-significant.

The difference in the rate of major and minor amputations among the two groups was also found to be statistically non- significant. This is in concordance with other studies whichobserved that MDRO per se does not increase the rate of amputations. ${ }^{12}$ Other factors like poor compliance with off-loading and antibiotics, vascular compromise and advanced stage diabetes are more important in deciding amputations among these patients. ${ }^{13}$ But, because of resistant nature of pathogens, MDRO may require more surgical interventions as compared to patients with non-MDRO. Multiple procedures were required in $50 \%$ of patients with MDRO as compared to $48 \%$ of patients with non-MDRO. Gadepalli et al. and others also observed that patients with MDRO required significantly more surgical treat-

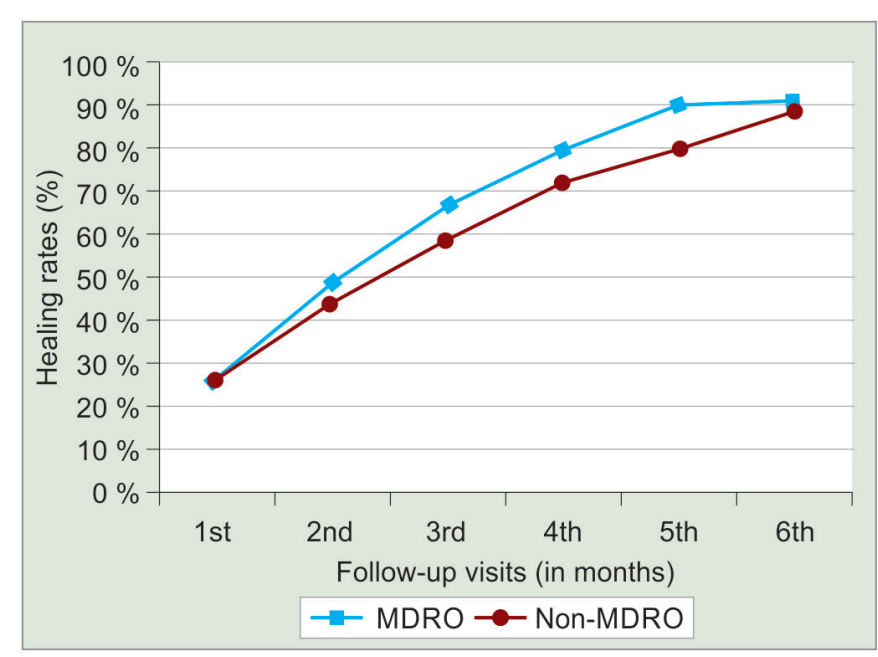

Fig. 1: Mean healing rate at follow-up (MDRO versus non-MDRO)

ment as compared to patients with non-MDRO (81\% and $45 \%$ respectively) with $\mathrm{p}$-value $<0.01 .^{14}$

Although the mean duration of hospital stay was slightly more in patients with MDRO (19.15 +/- 12.95 days) as compared to patients with non-MDRO (17.65 +/- 8.05 days ( $p$-value $=0.986)$. Dang et al. reported that there is no increase in hospitalization because of MRSA infection in patients with DFI. ${ }^{15}$ Lavery et al. also observed that length of hospital stay is not prolonged by the presence of MRSA in DFI. ${ }^{16}$ The duration of hospital stay may also depend on the management policy of the hospital. In our hospital, patients are discharged once the healing begins and glycemic control is attained and patients are advised to come for follow-up regularly in diabetic foot clinic.

The effect of MDROs on ulcer healing is still not clear. Mean healing rate at the 6th month of follow-up in our patients with MDRO was $91.25 \%$ and in patients with non-MDRO was $88.29 \%$. However, this difference was statistically not significant $(p$-value $=0.504)$. Various other authors also observed that the presence of MDRO is not associated with a significant difference in healing time or percentage of hea led wounds. ${ }^{17,18}$ The rapid reaction against MDRO and similar in vivo virulence of both MRSA and MSSA have been proposed as reasons for the absence of healing difference among the two groups. ${ }^{17,19}$ In our department we also have the policy to start antiMRSA on the first visit especially when bone is found to be involved on clinical examination. Then further therapy is decided based on microbiological results. This early reaction to $\mathrm{MDRO}$ is probably the reason for similar wound healing seen among two groups. Furthermore, on multivariate analysis, Richard et al. found that wound depth and severity, neuroischemic ulcer, Hb1Ac level, and proliferative retinopathy influence ulcer healing more as compared to the drug-resistant status of microorganisms. ${ }^{13}$ On the contrary, Dang et al. in their study reported 
that MRSA infection was associated with slower ulcer healing. ${ }^{15}$ Tentolouris et al. also observed that patients with MRSA had significantly longer healing time than patients whose ulcers were infected by MSSA. ${ }^{20}$

The small number of cases may limit statistical conclusions about the true differences between two groups but it seems, from our experience where treatment is based on early anti-MDRO and aggressive surgical treatment, that MDRO infections are not associated with worse prognosis in patients with DFI.

\section{REFERENCES}

1. Lavery LA, Armstrong DG, Murdock DP, Peters EJ, Lipsky BA. Validation of the infectious diseases society of America's diabetic foot infection classification system. Clin Infect Dis 2007 Feb;44:562-565.

2. Lipsky BA, Berendt AR, Deery HG, Embel JM, Joseph WS, Karchner AW et al. Infectious Diseases Society of America diagnosis and treatment of diabetic foot infection. Clin Infect Dis 2004 Oct;39:885-910.

3. Siegel JD, Rhinehart E, Jackson, Chiarello L. Management of Multidrug-Resistant Organisms In Healthcare Settings 2006. https://www.cdc.gov/infectioncontrol/guidelines/mdro. Accessed 13 July 2017.

4. Eleftheriadou I, Tentolouriis N, Argiana V, Jude E, Boulton AJ. Methicillin-resistant Staphylococcus aureus in diabetic foot infections. Drugs 2010 Oct;70:1785-1797.

5. Harteman-Heurtier A, Robert J, Jacqueminet S, Ha Van G, Golmard JL, Jarlier V. Diabetic foot ulcer and multidrugresistant organisms: risk factors and impact. Diabetic Med 2004 Jul;21:710-715.

6. Eckman MH, Greenfield S, Mackey WC, Wong JB, Kaplan S, Sullivan $\mathrm{L}$, et al. Foot infections in diabetic patients, decision and cost-effectiveness analysis. JAMA 1995 Mar;273:712-20.

7. Verma S, Joshi S, Chitnis V, Hemwani N, Chitnis D. Growing problem of methicillin resistant staphylococci-Indian scenario. Indian J Med Sci 2000 Dec;54:535-540.

8. Abramson MA, Sexton DJ. Nosocomial methicillin-resistant and methicillin-susceptible Staphylococcus aureus primary bacteremia: at what costs. Infect Control Hosp Epidemiol 1999 Jun;20:408-411.

9. Rello J, Torres A, Ricart M, Valles J, Gonzalez J, Artigas A et al. Ventilator-associated pneumonia by Staphylococcus aureus.
Comparison of methicillin-resistant and methicillin-sensitive episodes. Am J Respir Crit Care Med 1994 Dec;150:15451549.

10. Soriano A, Martinez JA, Mensa J, Marco F, Almela M, MorenoMartinez A et al. Pathogenic significance of methicillin resistance for patients with Staphylococcus aureus bacteremia. Clin Infect Dis 2000 Feb;30:368-373.

11. Harbarth S, Rutschmann O, Sudre P, Pittet D. Impact of methicillin resistance on the outcome of patients with bacteremia caused by Staphylococcus aureus. Arch Intern Med 1998 Jan; 158:182-189.

12. Sanchez JA, Martınez JLL, Marrero YQ, Herrero MJH, Morales EG, Galvan JJC, et al. Are diabetic foot ulcers complicated by MRSA osteomyelitis associated with worse prognosis? Outcomes of a surgical series. Diabet Med 2009 May;26:552555.

13.. Richard JL, Sotto A, Jourdan N, Combesecure C, Vannereau D, Rodier M, et al. Risk factors and healing impact of multidrugresistant bacteria in diabetic foot ulcers. Diabetes Med 2008 Sep; 34:363-369.

14. Gadepalli R, Dhawan B, Sreeenivasan V, Kapil A, Ammini AC, Chaudhary R. A clinico-microbioloical study of diabetic foot ulcers in an Indian tertiary care hospital. Diabetes Care 2006 Aug; 29:1727-1732.

15. Dang CN, Prasad YDM, Boulton AJM, Jude EB. Methicillinresistant Staphylococcus aureus in the diabetic foot clinic: a worsening problem. Diabet Med 2003 Feb; 20:159-161.

16. Lavery LA, Fontaine JL, Bhavan K, Kim PJ, Williams JR, Hunt NA. Risk factors for methicillin-resistant Staphylococcus aureus in diabetic foot infections. Diabetic foot ankle 2014 Apr;5:23575.

17. Harteman-Heurtier A, Robert J, Jacqueminet S, Ha Van G, Golmard JL, Jarlier V, et al. Diabetic foot ulcer and multidrugresistant-organisms: risk factors and impact. Diabet Med 2004 Jul;21:710-715.

18. Game FL, Boswell T, Soar C, Houghton E, Treece KA, Pound $\mathrm{M}$, et al. Outcome of diabetic foot ulcers with and without Staphylococcus aureus (MRSA). Diabet Med 2003 Jul;20:30.

19. Mizobuchi S, Minami J, Jin F, Matsushita O, Okabe A. Comparison of the virulence of methicillin-resistant and methicillin-sensitive Staphylococcus aureus. Microbiol Immunol 1994 Aug;38:599-605.

20. Tentolouris N, Jude EB, Smirnof I, Knowles EA, Boulton AJ. Methicillin-resistant Staphylococcus aureus: an increasing problem in diabetic foot clinic. Diabet Med 1999 Sep;16:767771. 